\title{
Reducing hip fractures in the elderly
}

\author{
This article was published in the following Dove Press journal: \\ Clinical Interventions in Aging \\ 10 March 201 I \\ Number of times this article has been viewed
}

\section{Victoria Leytin \\ Francesca L Beaudoin \\ Department of Emergency Medicine, Rhode Island Hospital, The Warren Alpert Medical School of Brown University, Providence, RI, USA}

Date of preparation: 6th December 2010 Conflict of interest: None declared
Correspondence: Francesca Beaudoin Department of Emergency Medicine, 593 Eddy Street, Claverick 2,

Providence, RI 02903, USA

Email Francesca_Beaudoin@brown.edu
Clinical question: Is there evidence that hip protectors and vitamin D with calcium supplementation reduce hip fractures in the elderly?

Results: The results are that vitamin D and calcium supplementation reduce incidence of hip fractures. Hip protectors provide some benefit in reducing hip fractures in elderly patients in residential facilities.

Implementation: Primary care providers should assess patients for the risk of hip fracture and consider using hip protectors and nutritional supplementaton in selected individuals to prevent fractures.

Keywords: hip fracture, hip protector, vitamin D, calcium

\section{Hip fractures}

Definition: The term 'hip fractures' encompasses five subtypes of fractures of the proximal femur: femoral head, femoral neck, intertrochanteric, trochanteric, and subtrochanteric. This is a common orthopedic emergency with $\sim 1.7$ million hip fractures occurring annually worldwide. Due to the aging population, it is estimated that by 2050 , there will be 6.26 million hip fractures worldwide. ${ }^{1}$

Etiology: The vast majority of hip fractures afflicts the elderly and generally occurs with low mechanism injuries, such as falls from standing. Osteoporosis is the predominant risk factor. However, the risk of hip fracture is also much higher for elders in residential dwellings when compared to those in the community. This is in part because more debilitated elders are both more likely to fall and more likely to have lost mechanisms to protect themselves during a fall. The term 'residential' elder refers to those elderly patients who are housed in nursing homes or assisted living facilities, in contradistinction to 'community-dwelling' elders who reside outside of such institutions.

Economics: Hip fractures are associated with significant morbidity and mortality and impose a large economic burden. In the United States, the average cost for inpatient hip fracture care is $\$ 26,000$ per episode. There is also significant cost attributable to the disability of hip fractures, largely related to skilled nursing care. Few patients regain their former level of independence after sustaining a hip fracture, and mortality rates at 1 year have been reported at $10 \%-20 \%$. $^{2}$ The lifetime attributable cost of hip fractures has been estimated to be $\$ 81,000$ per person in the United States. The projected annual cost of hip fractures in the United States is \$16 billion in 2020. Worldwide, the direct and indirect costs of hip fractures are estimated to be US \$131 billion annually. ${ }^{3}$ 
Level of evidence used in this summary: Systematic reviews, meta-analyses, and randomized controlled trials (RCTs) were analyzed.

Search sources: The search engines used for this study were PubMed, Cochrane library, NHS evidence, HTA database, and DARE.

Outcomes: From the patient perspective, the main outcomes are:

1. Decreased incidence of hip fractures

2. Compliance with intervention

3. Occurrence of complications with the intervention
Consumer summary: Hip fractures usually occur in the elderly after suffering a minor fall. Osteoporosis is the main risk factor for hip fractures. Therefore, prevention of hip fractures should naturally focus on prevention of falls and osteoporosis, as well as reducing the risk of fracture resultant from a fall. The two common recommended preventative measures are reviewed. There is good evidence that vitamin D plus calcium supplementation are preventative against hip fractures and some evidence that hip protectors can also be preventative in certain groups of high-risk elders. Although this article does not address other measures, such as bisphosphonates or estrogen replacement therapy, these may be beneficial and should also be considered for patients at risk for osteoporosis.

\section{The evidence}

\section{Do hip protectors reduce the incidence of hip fractures after a fall?}

Systematic reviews: 3

Meta-analysis:

RCTs:

In biomechanical studies, hip protectors (hard more so than soft) have been shown to reduce the peak pressure upon the hip during falls. ${ }^{4,5}$ However, in clinical trials, hip protectors have only been shown to be of modest benefit in the reduction of hip fractures. The more robust results come from data of nursing home residents and those at higher risk for fracture.

The Cochrane systematic review concluded that hip protectors marginally diminish the risk of hip fracture in nursing and residential care settings $(4.2 \%$ vs $6.2 \%$; relative risk [RR], 0.77; 95\% confidence intervals [CI]: 0.62-0.97), but not in community-dwelling elders (3.5\% vs $2.8 \%$; RR, 1.16 ; 95\% CI: $0.85-1.59) .{ }^{6}$ Two other systematic reviews reached similar conclusions, namely, that hip protectors significantly reduce the risk of hip fracture in nursing homes. The authors recommended use of hip protectors for residential-dwelling elders. ${ }^{7,8}$

The meta-analysis by Sawka et al reached similar conclusions regarding effectiveness of hip protectors and was later included in the 2010 systematic review by the same author. ${ }^{8,9}$

The two most recent RCTs, with conflicting results, are shown in Table $1 .^{10,11}$

Lack of adherence to the therapy continues to be a limiting factor, and it is more pronounced outside of nursing home settings. Up to $70 \%$ of both community and residential elders are not compliant at follow-up, although the adherence figures are highly variable between studies. The most commonly reported complications with hip protectors are skin irritation and lack of comfort, as well as increased need for nursing care.

Table I The two most recent RCTs with conflicting results ${ }^{10,11}$

\begin{tabular}{lllll}
\hline Author & Population & No. enrolled & Compliance & Conclusion \\
\hline Koike, et a ${ }^{11}$ & High-risk residential elders & 672 & $79.7 \%$ & Hip protectors effective at reducing \\
Kiel, et a ${ }^{10}$ & Nursing home residents & 531 & $73.8 \%$ & Ineffective at preventing hip fractures \\
\hline
\end{tabular}

\section{Conclusion}

Hip protectors are helpful to reduce incidence of hip fractures in residential, high-risk patients. Community elders do not benefit from the use of hip protectors. Overall, there is poor adherence to this intervention. Most common complications are skin irritation and discomfort.

\section{Does vitamin $D$ and calcium} supplementation reduce the risk of hip fracture?

Systematic reviews: $\quad 4$

Meta-analysis:
3 
Extensive analyses have been carried out examining the effect of vitamin $\mathrm{D}$, with or without calcium supplementation, in prevention of hip fractures. Although the evidence is not consistent, there seems to be a beneficial effect to high-dose vitamin D supplementation, especially when combined with calcium. The current National Institutes of Health daily intake recommendations are 400 international units (IU) (51-70 years) or $600 \mathrm{IU}$ ( $>70$ years) of vitamin D and $1200 \mathrm{mg}$ of calcium $(>51$ years $)$.

The largest systematic review looked at 45 randomized trials in total. This systematic review concluded, on the basis of nine trials $(24,749$ participants), that vitamin D alone is not likely to be effective in preventing hip fractures. However, based on eight trials (445,658 participants), vitamin D plus calcium (when compared to placebo) demonstrated a significant reduction in the incidence of hip fractures. Similarly, regarding hip protectors, they also concluded that residential-dwelling elders derived the most benefit. ${ }^{12}$

The three other systematic reviews concluded that highdose vitamin $\mathrm{D}$ was beneficial with greatest benefit derived when supplemented with calcium and in a residential elderly population. No effect was found with low-dose vitamin D supplementation in any of the trials reviewed. ${ }^{8,13,14}$

A high-powered meta-analysis of 29 randomized trials (63,897 participants) examining calcium supplementation found a $12 \%$ risk reduction of any type of fracture, including hip fractures. ${ }^{15}$ This effect was more pronounced in older patients ( $>70$ years), those with lower body weight, and those elders in residential dwelling. The treatment effect was bigger with high-dose calcium supplementation $(>1200 \mathrm{mg}$ /day) and with high vitamin D doses (>800 IU/day). Interestingly, the treatment was shown to be similarly effective with use of calcium alone as with calcium in combination with vitamin D. The protective effect was found to be greater in studies with high compliance. Except for one recent meta-analysis, those that were reviewed concluded that vitamin D plus calcium was superior to vitamin $\mathrm{D}$ alone. ${ }^{15-18}$

Table 2 summarizes the systematic reviews and recent meta-analyses of vitamin $\mathrm{D}$ alone versus vitamin and calcium supplementation for prevention of hip fractures.

The most commonly reported side effects from the use of vitamin D and calcium are gastrointestinal symptoms,

Table 2 Summary of systematic reviews and recent meta-analyses of vitamin D alone versus vitamin and calcium supplementation for prevention of hip fractures

\begin{tabular}{|c|c|c|c|c|}
\hline Author & Type & Vitamin D alone & $\begin{array}{l}\text { Vitamin D } \\
\text { and Calcium }\end{array}$ & Conclusion \\
\hline Avenell, et al ${ }^{12}$ & $\begin{array}{l}\text { Review of } 45 \\
\text { RTCs }\end{array}$ & Not beneficial & Beneficial & $\begin{array}{l}\text { Recommend combined vitamin D and calcium } \\
\text { supplementation in frail older people in } \\
\text { institutions. Unclear effect on community dwellers }\end{array}$ \\
\hline $\mid z a k s$, et al $\left.\right|^{14}$ & $\begin{array}{l}\text { Review of II } \\
\text { RCTs }\end{array}$ & $\begin{array}{l}\text { Not beneficial } \\
\text { (low dose) }\end{array}$ & Beneficial & $\begin{array}{l}\text { Vitamin D (high dose) and calcium showed } \\
\text { decreased fracture risk in institutionalized } \\
\text { patients. Low dose vitamin D is ineffective, and } \\
\text { there is not sufficient data on high dose vitamin D } \\
\text { alone }\end{array}$ \\
\hline MacLean, et $\mathrm{al}^{13}$ & Review of 7 RCTs & Beneficial & Beneficial & $\begin{array}{l}\text { Vitamin D with or without calcium } \\
\text { supplementation reduces risk of nonvertebral } \\
\text { fractures. One study of calcium supplementation } \\
\text { alone showed no effect }\end{array}$ \\
\hline Sawka, et $\mathrm{al}^{9}$ & Review of 7 RCTs & Beneficial & Beneficial & $\begin{array}{l}\text { High dose vitamin D supplementation with or } \\
\text { without calcium reduces risk of hip fracture }\end{array}$ \\
\hline Tang, et $\mathrm{al}^{15}$ & $\begin{array}{l}\text { Meta-analysis of } \\
29 \text { RCTs }\end{array}$ & Not investigated & Beneficial & $\begin{array}{l}\text { Calcium alone or in combination with vitamin } D \\
\text { is effective at preventing fractures. Both are more } \\
\text { effective in high doses }\end{array}$ \\
\hline $\begin{array}{l}\text { Bischoff-Ferrari, } \\
\text { et } \mathrm{al}^{16}\end{array}$ & Review of 7 RCTs & Unable to determine & Beneficial & $\begin{array}{l}\text { High dose vitamin D supplementation with calcium } \\
\text { reduces risk of hip and nonvertebral fracture in } \\
\text { community and institutionalized settings }\end{array}$ \\
\hline Jackson, et al ${ }^{17}$ & $\begin{array}{l}\text { Meta-analysis of } 9 \\
\text { RCTs }\end{array}$ & Not beneficial & Not beneficial & $\begin{array}{l}\text { Though no statistically significant fracture } \\
\text { reduction demonstrated, there was a trend } \\
\text { toward reduced risk }\end{array}$ \\
\hline Bergmana, et al ${ }^{18}$ & $\begin{array}{l}\text { Meta-analysis of } 8 \\
\text { RCTs }\end{array}$ & Not investigated & Beneficial & $\begin{array}{l}\text { Vitamin D3 and calcium supplementation reduced } \\
\text { hip fractures as compared to placebo }\end{array}$ \\
\hline
\end{tabular}


renal disease, and hypercalcemia. All of these were modestly but significantly increased in patients receiving treatment versus placebo. According to the systematic review by the Cochrane Collaboration, related vitamin $\mathrm{D}$

\section{Conclusion}

High-dose vitamin D (800 IU) and calcium (1200 mg) in combination are effective at reducing risk of hip fracture, compounds used do not seem to have advantages when compared to vitamin D, and calcitriol, specifically, may be deleterious through an increase of documented adverse events.

especially in institutionalized elderly patients. Adverse events, though rare, can include hypercalcemia and renal disease.

\section{The practice}

\section{Potential pitfalls}

- Monitor patients for side effects of treatments, such as skin irritation in the case of hip protectors or hypercalcemia and renal disease in the case of vitamin D and calcium supplementation.

- Monitor and control risk factors for osteoporosis.

- Do not fail to recognize reasons for fracture other than osteoporosis, such as elder abuse or pathologic fracture.

- Investigate cause of frequent falls.

- Recognize the high morbidity and mortality of osteoporotic fractures.

\section{Management}

Primary providers should screen for both risk factors for osteoporosis and the disease itself, including bone density screening. Consider vitamin D and calcium supplementation in high-risk individuals. Hip protectors should be considered for residential elders and those at high-risk of hip fracture.

\section{Assessment}

Screen for risk factors for osteoporosis (such as tobacco use, low body weight, high alcohol intake, use of steroids, and physical inactivity) and for falls (such as alcohol or substance abuse, underlying medical conditions, poor mobility, vision, cognition, and unsafe environments). Interventions should also be aimed at reduction of these risk factors.

\section{Treatment}

- Dose vitamin D at $800 \mathrm{IU}$ per day and calcium at $1200 \mathrm{mg}$ per day.

- Hip protectors may be obtained from numerous commercial vendors. They are available in a variety of styles and sizes, including specific models designed for elders with incontinence.
- In this article, we addressed two commonly utilized methods of hip fracture prevention. There are many more options available for prevention of osteoporosis and secondarily hip fractures, including bisphosphonates and estrogen modulators. These therapies were beyond the scope of this review; further reading on these topics is recommended below.

\section{Indications for specialist referral}

Preventative measures for osteoporosis and hip fractures can be instituted by primary care physicians and do not require specialist referral.

\section{Further reading}

Cranney A, Guyatt G, Griffith L, et al. Meta-analyses of therapies for postmenopausal osteoporosis. IX: Summary of meta-analyses of therapies for postmenopausal osteoporosis. Endocr Rev. 2002 Aug;23(4):570-8.

Lewiecki EM. Prevention and treatment of postmenopausal osteoporosis. Obstet Gynecol Clin North Am. 2008;35(2):301-315, ix.

\section{References}

1. Cooper C, Campion G, Melton LJ, 3rd. Hip fractures in the elderly: a world-wide projection. Osteoporos Int. 1992;2(6):285.

2. Trombetti A, Herrmann F, Hoffmeyer P, Schurch MA, Bonjour JP, Rizzoli R. Survival and potential years of life lost after hip fracture in men and age-matched women. Osteoporos Int. 2002;13(9): 731-737.

3. Burge R, Dawson-Hughes B, Solomon DH, Wong JB, King A, Tosteson A. Incidence and economic burden of osteoporosis-related fractures in the United States, 2005-2025. J Bone Miner Res. 2007;22(3):465-475.

4. Choi WJ, Hoffer JA, Robinovitch SN. In simulated falls, hip protectors work. Clin Biomech. 2010;25(1):63-69.

5. Bentzen H, Bergland A, Forsén L. Risk of hip fractures in soft protected, hard protected, and unprotected falls. Inj Prev. 2008;14(5):306-310.

6. Gillespie WJ, Gillespie LD, Parker MJ. Hip protectors for pre venting hip fractures in older people. Cochrane Database Syst Rev. 2010;10:CD001255.

7. Parker MJ, Gillespie WJ, Gillespie LD. Effectiveness of hip protectors for preventing hip fractures in elderly people: systematic review. $B M J$. 2006;332(7541):571-574.

8. Sawka AM, Ismaila N, Cranney A, et al. A scoping review of strategies for the prevention of hip fracture in elderly nursing home residents. PLoS One. 2010;5(3):e9515. 
9. Sawka AM, Boulos P, Beattie K, et al. Hip protectors decrease hip fracture risk in elderly nursing home residents: a Bayesian meta-analysis. J Clin Epidemiol. 2007;60(4):336-344.

10. Kiel D, Magaziner J, Zimmerman S, et al. Efficacy of a hip protector to prevent hip fracture in nursing home residents: the HIP PRO randomized controlled trial. JAMA. 2007;298(4):413-422.

11. Koike T, Orito Y, Toyoda H, et al. External hip protectors are effective for the elderly with higher-than-average risk factors for hip fractures. Osteoporos Int. 2009;20(9):1613-1620.

12. Avenell A, Gillespie WJ, Gillespie LD, O'Connell D. Vitamin D and vitamin D analogues for preventing fractures associated with involutional and post-menopausal osteoporosis. Cochrane Database Syst Rev. 2009;2:CD000227.

13. MacLean C, Newberry S, Maglione M, et al. Systematic review: comparative effectiveness of treatments to prevent fractures in men and women with low bone density or osteoporosis. Ann Intern Med. 2008;148(3):197-213.
14. Izaks GJ. Fracture prevention with vitamin D supplementation: considering the inconsistent results. BMC Musculoskelet Disord. 2007;8:26.

15. Tang BM, Eslick GD, Nowson C, Smith C, Bensoussan A. Use of calcium or calcium in combination with vitamin D supplementation to prevent fractures and bone loss in people aged 50 years and older: a meta-analysis. Lancet. 2007;370(9588):657-666.

16. Bischoff-Ferrari HA, Willett WC, Wong JB, Giovannucci E, Dietrich T, Dawson-Hughes B. Fracture prevention with vitamin D supplementation: a meta-analysis of randomized controlled trials. JAMA. 2005;293(18):2257-2264.

17. Jackson C, Gaugris S, Sen SS, Hosking D. The effect of cholecalciferol (vitamin D3) on the risk of fall and fracture: a meta-analysis. QJM. 2007;100(4):185-192.

18. Bergman GJ, Fan T, McFetridge JT, Sen SS. Efficacy of vitamin D3 supplementation in preventing fractures in elderly women: a meta-analysis. Curr Med Res Opin. 2010;26(5):1193-1201.
Clinical Interventions in Aging

\section{Publish your work in this journal}

Clinical Interventions in Aging is an international, peer-reviewed journal focusing on evidence-based reports on the value or lack thereof of treatments intended to prevent or delay the onset of maladaptive correlates of aging in human beings. This journal is indexed on PubMed Central, MedLine, the American Chemical Society's 'Chemical Abstracts Ser-

\section{Dovepress}

vice' (CAS), Scopus and the Elsevier Bibliographic databases. The manuscript management system is completely online and includes a very quick and fair peer-review system, which is all easy to use. Visit http://www.dovepress.com/testimonials.php to read real quotes from published authors. 